\title{
Solubility Augmentation of Simvastatin by using the Marvelous Carrier Hydroxy Propyl $\beta$-cyclodextrin: Compatibility Study, Statistical and Spectral Analysis
}

\author{
Disha Kesharwani ${ }^{1, *}$, Sandhya Mishra ${ }^{1}$, Swarnali Das Paul' ${ }^{2}$ Rishi Paliwal ${ }^{3}$, Trilochan Satapathy ${ }^{1}$ \\ ${ }^{1}$ Columbia Institute of Pharmacy, Raipur, Chhattisgarh, INDIA. \\ ${ }^{2}$ Faculty of Pharmaceutical Sciences, SSTC, SSGI, Bhilai, Chhattisgarh, INDIA. \\ ${ }^{3}$ Faculty of Pharmacy, IGNTU, Amarkantak, Madhya Pradesh, INDIA.
}

\begin{abstract}
Objective: The poor solubility which causes the poor bioavailability of simvastatin is an arduous task for the preparation of oral dosage form, which can be increased by the preparation of solid dispersion. Materials and Methods: The solid dispersions of simvastatin were prepared in different ratios by physical mixture method, kneading method and melting method using PEG 6000, $\beta$-cyclodextrin and Hydroxy Propyl $\beta$-cyclodextrin to enhance the solubility of poorly soluble drug. Results: These solid dispersions were analyzed for the solubility by prescribed methods. The solid dispersion of drug with HP $\beta$-cyclodextrin in 1:1 ratio has shown enormously improved solubility. Further FTIR and X-Ray studies were carried out. The compatibility study showed that there is no interaction between the drug and HP $\beta$-cyclodextrin and PXRD confirmed the amorphization of crystalline drug. Conclusion: The overall result showed that the solid dispersion of simvastatin can be prepared by various methods, of which the kneading method was best with HP $\beta-C D$ in 1:1 (drug: polymer) ratio, in comparison with melting and physical mixture method. Hence we can conclude that the solubility of simvastatin can be enhanced using HP $\beta-C D$.
\end{abstract}

Key words: Solid dispersion, HP $\beta$-cyclodextrin, PXRD, HMG Co A reductase, complexation.

\section{INTRODUCTION}

Many drugs have a major challenge of poor bioavailability, during their selection for oral drug delivery. So, enhancement of bioavailability, or its solubility is of great importance. Many techniques were discovered to overcome these shortcomings which include salt formation, prodrug formation, particle size reduction, complexation, micelles, microemulsions, nanoemulsions, nanosuspensions, solid lipid nanoparticles and solid dispersions. Amongst these methods, solid dispersion method is the most widely used method. ${ }^{1}$ However there are certain limitations like problems during preparation of SD of many drugs and recrystallization during storage but many studies have shown that use of many polymers like PEG
6000 in the preparation of SD can lead to preparation of a stable amorphous SD with no chance of recrystallization on storage. In the recent years bioavailability of many drug have been increased by solid dispersion techniques which results in reduced particle size and enhanced surface contact which helps them in enhancing dissolution rate. ${ }^{2,3}$ Solid dispersions not only enhance the drug solubility and stability but also make the drug palatable. There are number of methods available for preparation of solid dispersion which include melting or fusion method, solvent evaporation method, kneading methods and many more. ${ }^{4,5}$
Submission Date: 26-04-2019; Revision Date: 03-06-2019; Accepted Date: 04-07-2019

DOI: 10.5530/ijper.53.3s.92 Correspondence: Ms. Disha Kesharwani, Columbia Institute of Pharmacy, Raipur-492001, Chhattisgarh, INDIA. Phone: +917389647188 E-mail: kesharwanidisha08@ gmail.com

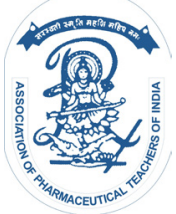

www.ijper.org 
Simvastatin (BCS II drug) is a white crystalline powder. Its chemical name is (1S,3R,7S,8S,8aR)-1,2,3,7,8,8ahexahydro-3,7-dimethyl-8-[2-[(2R,4R)-tetrahydro-4hydroxy-6-oxo-2H-pyran-2yl]ethyl]-1-naphthalenyl ester. ${ }^{2}$ It belongs to anti-hyperlipidemic drug category and acts by inhibiting the enzyme 3- hydroxy-3-methylglutaryl-coenzyme-A (HMG Co-A) reductase, the enzyme that catalyses an early and rate limiting step in the biosynthesis of cholesterol. ${ }^{6}$ Simvastatin has poor aqueous solubility and bioavailability as it belongs to BCS class-II drug so preparation of solid dispersion is a beneficial tool for increasing its bioavailability.

\section{MATERIALS AND METHODS}

\section{Materials}

The gift sample of Simvastatin was received from Dr. Reddys' Pharmaceuticals' Ltd. Hyderabad. The Hydroxy Propyl Methyl Cellulose (HPMC) and Methyl cellulose (MC) polymers were gifted from Signet Chemicals Pvt. Ltd and Loba Chem Pvt. Ltd Mumbai. The other chemicals are ethanol, methanol, magnesium state, talc, lactose; disodium hydrogen orthophosphate and potassium dihydrogen orthophosphate were purchased from Loba Chemicals Mumbai, India.

\section{Methods}

(A) Physiochemical and Analytical Characterization of Pure Drug: The drug sample (Simvastatin) was analyzed by different means such as color, odor, texture, melting point, absorption maxima, FTIR study etc. in order to prove the authenticity of the sample.

(i) Organoleptic Test: The Organoleptic tests (Color, odor, taste) were observed.

Color: determined visually

Odor: determined

Texture: determined visually and by touch

(ii) Melting Point Test: The melting point of the drug was determined by capillary method using the melting point apparatus. Firstly one end of the capillary tube was sealed. Then the drug was powdered properly and filled up to three fourth heights into the capillary tube. The tube was then placed in the melting point apparatus and the melting point was recorded with the help of thermometer. The same procedure was repeated. ${ }^{8}$ Also the digital melting point apparatus was used for confirming the result.

(iii) Identification of drug by IR: FT-IR spectra of selected, drug were recorded on Shimadzu FT-IR spectrophotometer using $\mathrm{KBr}$ discs. The instrument was operated under dry air purge and the scans were col- lected at scanning speed $2 \mathrm{~mm} / \mathrm{sec}$ with resolution of 4 $\mathrm{cm}^{-1}$ over the region $4000-400 \mathrm{~cm}^{-1}$.

(iv) Determination of Absorption Maxima $\left(\lambda_{\max }\right)$ : $\lambda_{\max }$ of the drug was determined spectrophotometrically by using SIMADZU Spectrophotometer. A solution of $10 \mu \mathrm{g} / \mathrm{ml}$ concentration in phosphate buffer $\mathrm{pH} 7.0$ containing $0.5 \%$ SLS was scanned between $200-400 \mathrm{~nm}$. The same procedure was repeated with solution of $20 \mu \mathrm{g} / \mathrm{ml}$ concentration for confirmation.

(v) Preparation of Calibration Curve: Simvastatin was estimated spectrophotometrically at $247 \mathrm{~nm}$ by using phosphate buffer $\mathrm{pH} 7.0$ containing $0.5 \%$ SLS (Sodium Lauryl Sulphate) as solvent. ${ }^{10}$

- Preparation of Stock solution: A stock solution of simvastatin was prepared by dissolving $10 \mathrm{mg}$ of pure simvastatin in $10 \mathrm{ml}$ phosphate buffer $\mathrm{pH} 7.0$ containing $0.5 \%$ SLS to produce the concentration of $1000 \mu \mathrm{g} / \mathrm{ml}$ of simvastatin. The prepared solution was the stock solution.

- Preparation of Working Standard Solution: From the stock solution $2.5 \mathrm{ml}$ solution was taken and diluted up to $25 \mathrm{ml}$. The solution prepared was the working standard solution that contained 100 $\mu \mathrm{g} / \mathrm{ml}$.

- Preparation of Dilutions: From the working standard solution different dilutions were prepared of $5,10,15,20,25,30,35,40,45$ and $50 \mu \mathrm{g} / \mathrm{ml}$ by taking $0.5,1.0,1.5,2.0,2.5,3.0,3.5,4.0,4.5$ and $5.0 \mathrm{ml}$ and diluting up to $10 \mathrm{ml}$ each. Absorbance was measured with UV spectrophotometer at $247 \mathrm{~nm}$ using phosphate buffer $\mathrm{pH} 7.0$ as blank and plotted to get the calibration curve.

(B) Preparation of Solid Dispersion with $\beta-C D$ -

1. Physical Mixture: Drug, and HP $\beta-C D$ in the molar ratios of 1:1 were mixed in a mortar for about one hour with constant trituration, the mixture was passed through sieve no. 80 and stored in the desiccators over fused calcium chloride.

2. Kneading Method: First, cyclodextrin was placed in a mortar; a small quantity of $50 \%$ methanol was added to it while triturating to get slurry like consistency. Then the drug was slowly incorporated into the slurry and trituration was further continued for one hour. Slurry was then air dried at $25^{\circ} \mathrm{C}$ for $24 \mathrm{hr}$, pulverized, passed through sieve no. 80 and stored in desiccator over fused calcium chloride. ${ }^{11}$

3. Melting method: Accurately weighed carrier (PEG 6000 ) was melted in a water bath at $70^{\circ} \mathrm{C}$, the drug was added in the solid state and the mixture stirred until homogeneity was attained. The mixture was then cooled rapidly in a freezing mixture of ice and stored in a desic- 
cator for $24 \mathrm{hr}$. Subsequently, the dispersion was grinded in a mortar and sieved through $80 .^{12}$

(C) Physiochemical and Analytical Characterization of Solid Dispersion of Simvastatin

\section{(i) Solubility Measurement}

The solubility of solid dispersions of simvastatin was determined in distilled water and phosphate buffer $\mathrm{pH}$ 7.0 containing $0.5 \%$ SLS according to USP dissolution profile of simvastatin. The solubility of inclusion complex of Simvastatin (SIM) and the Solid Dispersions (SD) prepared by physical mixture method and slugging method were determined by using the method, in which the mixture equivalent to $30 \mathrm{mg}$ of simvastatin were added in $10 \mathrm{ml}$ of the above solvents, in screw capped vials and kept at equilibrium for a period of 48 hr on mechanical shaker at $37 \pm 0.5^{\circ} \mathrm{C}$ and $50 \mathrm{rpm}$. The content of vials were filtered through $0.2 \mu \mathrm{m}$ filter and analyzed on UV-Visible spectrophotometer at $247 \mathrm{~nm} .{ }^{13}$

(ii) Phase Solubility Measurement

Solubility Determinations of Simvastatin using HP $\beta-C D-$

Solubility determinations were performed in triplicate according to the method of Higuchi and Connors. An excess amount of simvastatin was placed in a screw-cap glass vial to which $20 \mathrm{ml}$ of Phosphate buffer $\mathrm{pH} 7.0$ solution containing various concentrations $(0 \%, 2 \%$, $4 \%, 6 \%, 8 \%, 10 \%$ ) of HP $\beta$ - CD was added. The samples were shaken at $37 \pm 0.5^{\circ} \mathrm{C}$ for $72 \mathrm{hr}$ on a mechanical shaker. After $72 \mathrm{hr}$ the samples were filtered through a $0.45-\mu \mathrm{m}$ membrane filter. The filtrate was diluted 10 times and analyzed spectrophotometrically at $247 \mathrm{~nm}$ using a UV-Vis spectrophotometer (Shimadzu UV-1800, Switzerland). ${ }^{14}$

The value of the apparent stability constant, $K_{s}$, for drug-carrier combinations was computed from the phase-solubility profiles, as described by

$$
\mathrm{K}_{\mathrm{S}}=\frac{\text { Slope }}{\text { Intecept }(1-\text { Slope })}
$$

The Gibb's free energy of transfer $\left(\Delta G \operatorname{tr}^{\circ}\right)$ of simvastatin from phosphate buffer to solutions of carrier was calculated as

$$
\Delta \mathrm{G}_{\mathrm{tr}}=-2.303 \mathrm{RT}\left(\log \frac{\mathrm{S}_{0}}{\mathrm{~S}_{\mathrm{S}}}\right)
$$

Where $S_{0} / S_{S}$ is the ratio of the molar solubility of simvastatin in phosphate buffer of HP $\beta$ - CD to that in the same medium without HP $\beta$ - CD.

\section{(iii) Compatibility Study by FTIR-}

The FT-IR spectra of the pure drug, polymer mixture and optimized solid dispersion formulation were obtained to prove the chemical integrity of the drug in the solid dispersions.

Drug-polymer interactions were assessed by FT-IR spectroscopy. FT-IR spectra of selected dispersion powder, physical mixtures and drug were recorded on Shimadzu FT-IR spectrophotometer using $\mathrm{KBr}$ discs. The instrument was operated under dry air purge and the scans were collected at scanning speed $2 \mathrm{~mm} / \mathrm{sec}$ with resolution of $4 \mathrm{~cm}^{-1}$ over the region $4000-400 \mathrm{~cm}^{-1}$.

\section{(iv) Powder X- Ray Diffraction-}

Powder x-ray diffraction analysis has been used to characterize the physical state of the drug in the polymeric matrices of solid dispersions. The diffraction studies of the drug, polymer mixture and the optimized solid dispersion formulation were performed in a powder x-ray diffractometer with a vertical goniometer (PW 1050/37, Philips, Netherlands). PXRD patterns were recorded using monochromatic $\mathrm{Cu} \mathrm{K} \alpha$ radiation with $\mathrm{Ni}$ filter at a voltage of $40 \mathrm{kV}$ and a current of $20 \mathrm{~mA}$ between 5 to $80^{\circ} \mathrm{C} 2 \theta$ values. ${ }^{15}$

\section{RESULTS AND DISCUSSION}

\section{(A) Physiochemical and Analytical Characteriza-} tion of Pure Drug-

(i) Organoleptic Test- Color of Simvastatin - White to off - white Odor of Simvastatin - Odorless Taste of Simvastatin - Bitter, metallic taste.

(ii) Melting Point Test- The melting point of the pure drug simvastatin was found to be Theoretical Melting Point: $135-138^{\circ} \mathrm{C}$ Practical Melting Point: $126-135^{\circ} \mathrm{C}$.

The theoretical melting point of the pure drug is 135$138^{\circ} \mathrm{C}$ as per literature. The melting point determined by capillary method was $126-135^{\circ} \mathrm{C}$. So it is revealed that the drug was pure as there was no deviation from reported melting point. ${ }^{16}$

\section{(iii) Identification by FTIR-}

$>$ Figure 1 shows the FTIR spectra for pure simvastatin. Some of the characteristic infrared absorption bands were given in the Table 1 which corresponds the structure of simvastatin. ${ }^{12}$

\section{(iv) Determination of Absorption Maxima $\left(\lambda_{\max }\right)$ -}

$>$ Figure 2 shows the scanning spectra for $20 \mu \mathrm{g} / \mathrm{ml}$ dilution of pure drug. The $\lambda_{\max }$ of Simvastatin in phosphate buffer pH 7.0 was found to be $247 \mathrm{~nm}$. 


\begin{tabular}{|c|c|}
\hline BOND & FREQUENCY(in $\mathrm{cm}^{-1}$ ) \\
\hline $\mathrm{OH}$ stretching & 3549 \\
\hline Aromatic $\mathrm{CH}_{3}$ group & 2968 \\
\hline Aromatic $\mathrm{C}=\mathrm{O}$ stretching & 1724 \\
\hline
\end{tabular}

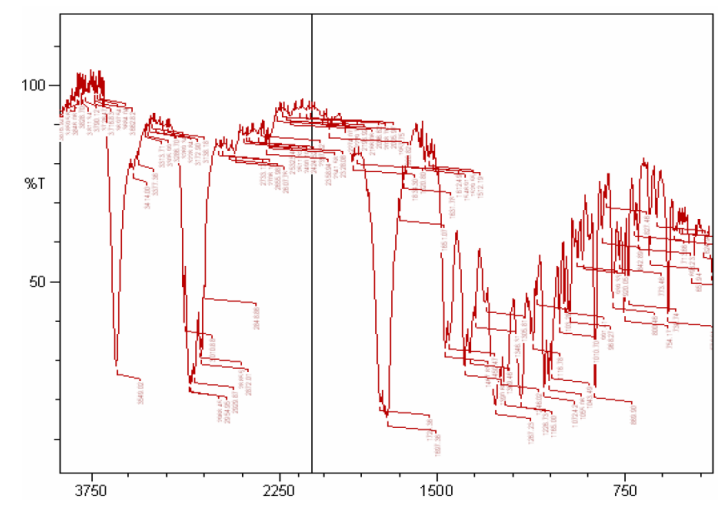

Figure 1: FTIR Spectra of Simvastatin (Pure Drug).

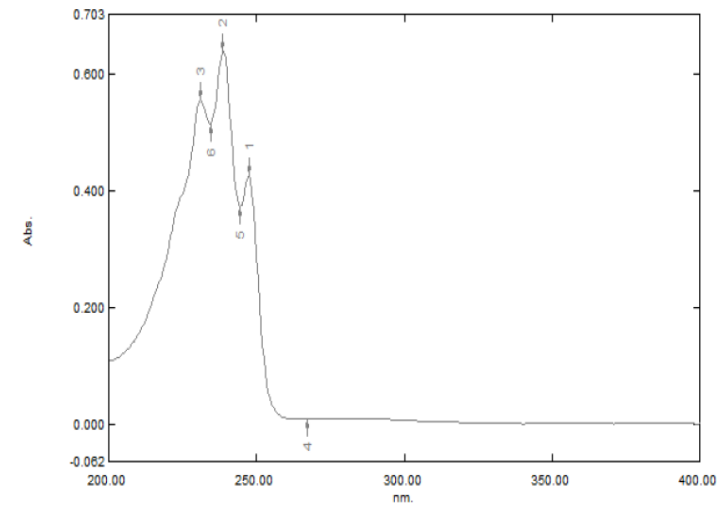

Figure 2: Spectra of $20 \mu \mathrm{g} / \mathrm{ml}$ dilution for $\lambda_{\max }$ Determination.

\section{(v) Preparation of Calibration Curve-}

Figure 3: Calibration Curve of Simvastatin with Phosphate Buffer pH 7.0 containing 0.5\% Sodium Lauryl Sulphate

The Linear regression equation obtained between concentration and their respective absorbance values and calibration curve is given in Figure 3. The equation obtained was:

$$
\begin{aligned}
& \mathrm{Y}=0.0397 \mathrm{x}+0.0386 \\
& \text { With } r^{2}=0.9991
\end{aligned}
$$

$>\quad$ The linear relationship between concentration and their respective absorbance values indicated that it obeyed the Beer's Lambert law.

(B) Different solid dispersions of simvastatin were prepared by using above methods

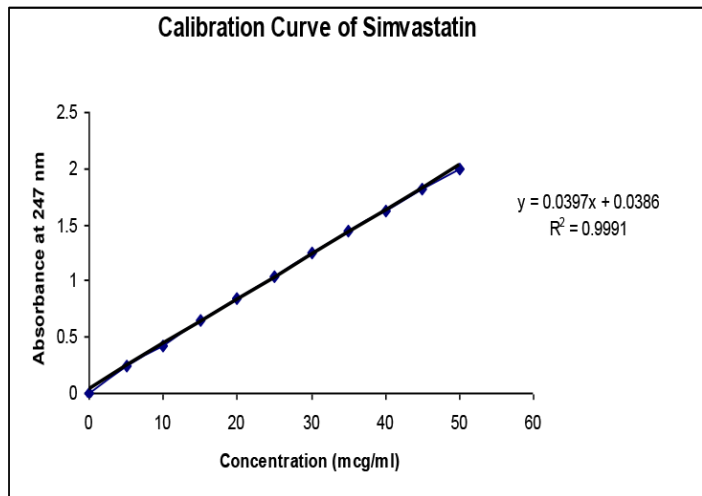

Figure 3: Calibration Curve of Simvastatin with Phosphate Buffer pH 7.0 containing $\mathbf{0 . 5} \%$ Sodium Lauryl Sulphate.

(C) Physiochemical and Analytical Characterization of Solid Dispersion of Simvastatin

\section{(i) Solubility Measurement-}

$>$ Solubility of drug in different solvents was given in Table 2 collected from literature.

The solubility values $(\mathrm{mg} / \mathrm{ml})$ of inclusion complex and solid dispersion with PEG 6000, $\beta$ Cyclodextrin and HP $\beta$ - Cyclodextrin are given in the Table 3, Table 4 and 5 respectively.

$>$ From the above experiment it was clear that the solubility was enhanced more with HP $\beta-\mathrm{CD}$ as compared to PEG 6000 and $\beta$ - CD. So from the two solubility enhancers HP $\beta$ - CD was selected for further study.

From the above experiment it can be concluded that the HP $\beta$ - CD by kneading method increased the solubility more than the physical mixture method.

So between the two methods kneading method was selected for preparation of inclusion complex for further study.

From the solubility data given in the above table, it can be conclude that there is a 6 fold increase in solubility of the drug at 1:1 ratio. With further increase in the amount of the HP $\beta$ - CD there was no significant increase in solubility. Only slight increase was found in the solubility with 1:2 ratio.

The improved solubility of simvastatin by complexation with HP $\beta$-CD by kneading method is due to formation of water soluble inclusion complexes with a variety of organic compounds, based on their ability to provide a hydrophobic cavity in aqueous solution for a hydrophobic guest molecule or hydrophobic moieties in the guest molecule. By complexation, cyclodextrins can increase the solubility, stability and bioavailability of the guest molecule. The enhancement of water 


\begin{tabular}{|c|c|c|}
\hline \multicolumn{3}{|c|}{ Table 2: Solubility of Simvastatin in Different } \\
Solvents. ${ }^{16}$
\end{tabular}

Table 3: Solubility values of Solid Dispersion with
PEG 6000.

\begin{tabular}{|r|c|c|c|c|}
\hline \multicolumn{5}{|c|}{$\begin{array}{c}\text { Table 4: Solubility values (mg/ml) of Inclusion } \\
\text { complex and Solid Dispersion with } \beta-\text { CD. }\end{array}$} \\
\hline $\begin{array}{r}\text { S. } \\
\text { No. }\end{array}$ & Simvastatin & $\begin{array}{c}\text { } \beta- \\
\text { Cyclodextrin }\end{array}$ & $\begin{array}{c}\text { Solubility } \\
\text { (mg/ml) By } \\
\text { Kneading } \\
\text { Method }\end{array}$ & $\begin{array}{c}\text { Solubility } \\
\text { (mg/ml) By } \\
\text { Physical } \\
\text { Mixture } \\
\text { Method }\end{array}$ \\
\hline 1 & 1 & --- & $0.420 \pm 0.46$ & $0.420 \pm 0.26$ \\
\hline 2 & 1 & 0.5 & $1.326 \pm 0.93$ & $0.465 \pm 0.74$ \\
\hline 3 & 1 & 1 & $2.481 \pm 0.19$ & $0.663 \pm 0.39$ \\
\hline 4 & 1 & 1.5 & $2.486 \pm 0.81$ & $0.821 \pm 0.61$ \\
\hline 5 & 1 & 2 & $2.528 \pm 0.38$ & $0.842 \pm 0.15$ \\
\hline
\end{tabular}

solubility of drugs is especially important for their bioavailability. ${ }^{17,18}$

Further with kneading method the solubility values for molar ratios 1:1 and 1:1.5 was almost similar. So the ratio 1:1 was selected for further study as with the further increase of the polymer there was not so much increase in the solubility.

The similarity between the two ratios was proved statistically by applying ANOVA.

ANOVA- Single factor- For determining the similarity between the two inclusion complexes (molar ratio 1:1 and 1:2) statistical approach (ANOVA- single factor) was applied.

Let null- hypothesis, $\mathrm{H}_{0}$ is that there is no significant difference between the solubility of the inclusion complexes with molar ratios, 1:1 and 1:1.5.
Table 5: Solubility values $(\mathrm{mg} / \mathrm{ml})$ of Inclusion complex and Solid Dispersion with HP $\beta-$ CD.

\begin{tabular}{|c|c|c|c|c|}
\hline $\begin{array}{c}\text { S. } \\
\text { No. }\end{array}$ & Simvastatin & $\begin{array}{c}\text { HP } \beta- \\
\text { Cyclodextrin }\end{array}$ & $\begin{array}{c}\text { Solubility } \\
\text { (mg/ml) By } \\
\text { Kneading } \\
\text { Method }\end{array}$ & $\begin{array}{c}\text { Solubility } \\
\text { (mg/ml) By } \\
\text { Physical } \\
\text { Mixture } \\
\text { Method }\end{array}$ \\
\hline 1 & 1 & --- & $0.490 \pm 0.36$ & $0.434 \pm 0.21$ \\
\hline 2 & 1 & 0.5 & $1.428 \pm 0.84$ & $0.481 \pm 0.65$ \\
\hline 3 & 1 & 1 & $2.496 \pm 0.31$ & $0.763 \pm 0.42$ \\
\hline 4 & 1 & 1.5 & $2.499 \pm 0.72$ & $0.853 \pm 0.52$ \\
\hline 5 & 1 & 2 & $2.517 \pm 0.41$ & $0.887 \pm 0.33$ \\
\hline
\end{tabular}

Table 6: Solubility Data for Kneading Method.

\begin{tabular}{|c|c|c|}
\hline \multirow{2}{*}{ Trial No. } & \multicolumn{2}{|c|}{ Solubility $(\mathbf{m g} / \mathrm{ml})$} \\
\cline { 2 - 3 } & $\mathbf{1 : 0 1}$ & $\mathbf{0 1 : 0 1 . 5}$ \\
\hline 1 & 2.481 & 2.486 \\
\hline 2 & 2.484 & 2.488 \\
\hline 3 & 2.483 & 2.487 \\
\hline
\end{tabular}

Table 6 shows again the solubility data for two ratios. From the Table 7 it can be concluded that the calculated F-value (0.000273) was less than the critical F- value (5.987). Hence the null hypothesis is accepted. So it can be revealed that there was no significant difference between the inclusion complexes with molar ratio 1:1 and 1:1.5. So the molar ratio 1:1 was selected for further study.

(ii) Phase Solubility Measurement

The phase-solubility data is mentioned in Table 8 and phase solubility diagram is shown in Figure 4 . The phase solubility profile is investigated in phosphate buffer $\mathrm{pH} 7.0$ is linear over a wide range of $\mathrm{HP} \beta$ - CD concentrations.

The values of the stability constant depend on slope values. The greater the value of the slope, the greater is the capacity of the polymer to solubilize the drug. The stability constant values vary slightly with polymer molecular weight. The values of the stability constants increase with increasing polymer molecular weight. These results agree with the well-established formation of soluble complexes between the water-soluble polymeric carriers and poorly water-soluble drugs.

Solubility of the drug improved that may be due to the conversion into amorphous form from the crystalline form and also due to improved wettability of the simvastatin particles in aqueous solution. Table 8 presented the values of the Gibb's free energy associated with the aqueous solubility of Simvastatin in the presence of HP $\beta$-CD. The 


\begin{tabular}{|c|c|c|c|}
\hline \multicolumn{4}{|c|}{ Table 7: ANOVA Table. } \\
\hline Factor & F- Calculated & F- Critical & $\begin{array}{c}\text { Significant } \\
\text { Level }\end{array}$ \\
\hline $\begin{array}{c}\text { Drug: HP } \\
\beta-C D\end{array}$ & 0.000273 & 5.987 & 0.05 \\
\hline
\end{tabular}

\begin{tabular}{|c|c|c|c|}
\hline$\%$ HP $\beta-C D$ & Absorbance & Concentration & $\Delta \mathbf{G}$ \\
\hline 0 & 0.061 & 0.132653061 & 0 \\
\hline 2 & 0.086 & 0.770408163 & -4359.2886 \\
\hline 4 & 0.119 & 1.612244898 & -6189.2120 \\
\hline 6 & 0.155 & 2.530612245 & -7306.3862 \\
\hline 8 & 0.186 & 3.321428571 & -7980.2430 \\
\hline 10 & 0.215 & 4.06122449 & -8478.5466 \\
\hline
\end{tabular}

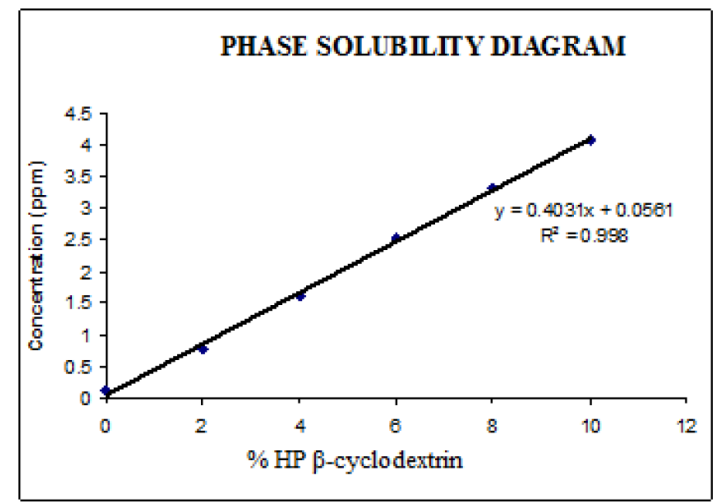

Figure 4: Phase Solubility Diagram.

$\Delta G \mathrm{tr}^{\circ}$ values are all negative for from $\mathrm{HP} \beta-\mathrm{CD}$ at various concentrations, indicating the spontaneous nature of solublization. ${ }^{14}$

\section{(iii) Compatibility Study by FTIR}

FT-IR has been used to assess the interaction between drug and excipients molecules in the solid state i.e. drug-polymer compatibility. The FT-IR spectra of pure drug, polymer and drugpolymer complex were given in Figure 5-7. Important vibrations detected shown in Table 9, in the spectrum of drug, polymers and formulations are described as follows:

(i) The spectrum of pure simvastatin presented characteristic peaks at $3550.31 \mathrm{~cm}^{-1}$ (alcoholic O-H stretching vibration), $2963.09 \mathrm{~cm}^{-1}$ and 2875.34 $\mathrm{cm}^{-1}$ (methyl and methylene C-H asymmetric and symmetric stretching vibration), $1704.76 \mathrm{~cm}^{-1}$ (lactone $\mathrm{C}=\mathrm{O}$ and ester $\mathrm{C}=\mathrm{O}$ stretching), 1464.67, $1388.50 \mathrm{~cm}^{-1}$ (methyl and methylene C-H bending vibration) and 1267.19, 1226.51, 1164.79 and

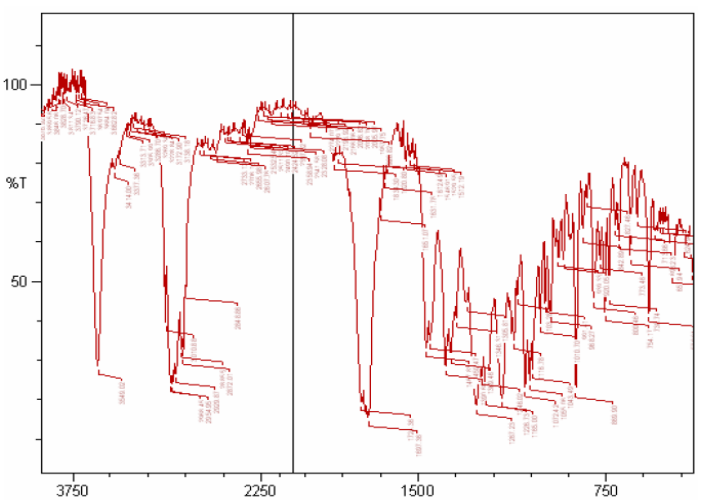

Figure 5: FTIR Spectra of Simvastatin (Pure Drug).

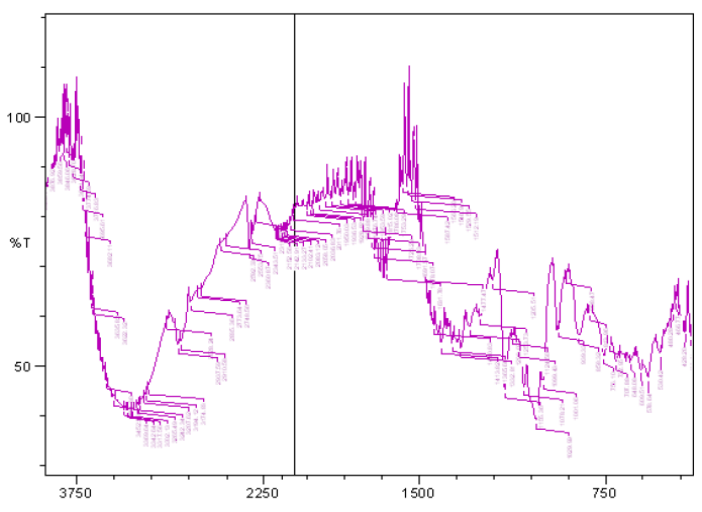

Figure 6: FTIR Spectra of HP $\beta$ - Cyclodextrin (HP $\beta$ - CD).

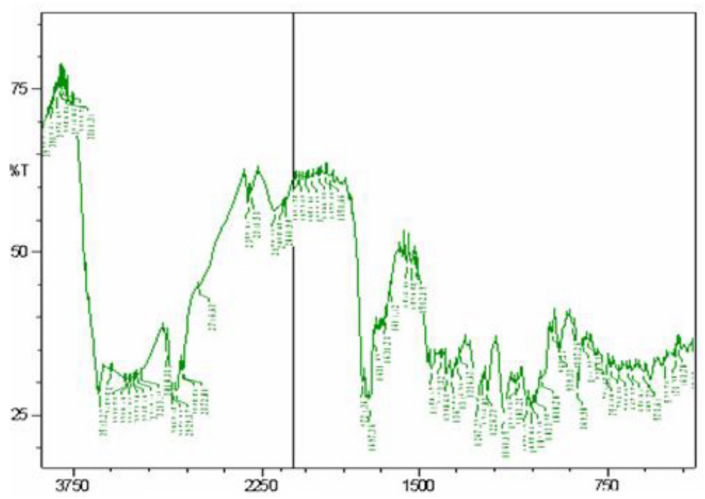

Figure 7: FTIR Spectra for Simvastatin +HP $\beta$ - Cyclodextrin $(\beta-C D)$.

$1121.40 \mathrm{~cm}^{-1}$ (lactone and ester $\mathrm{C}-\mathrm{O}-\mathrm{C}$ bending vibration), respectively.

(ii) It has been observed that the absorption bands of simvastatin pure drug and Simvastatin in inclusion complex remain unchanged. It shows that there is no interaction between drug and polymer molecules in the solid state. The drug is compatible with polymer. ${ }^{12}$

\section{(iv) Powder X- Ray Diffraction}




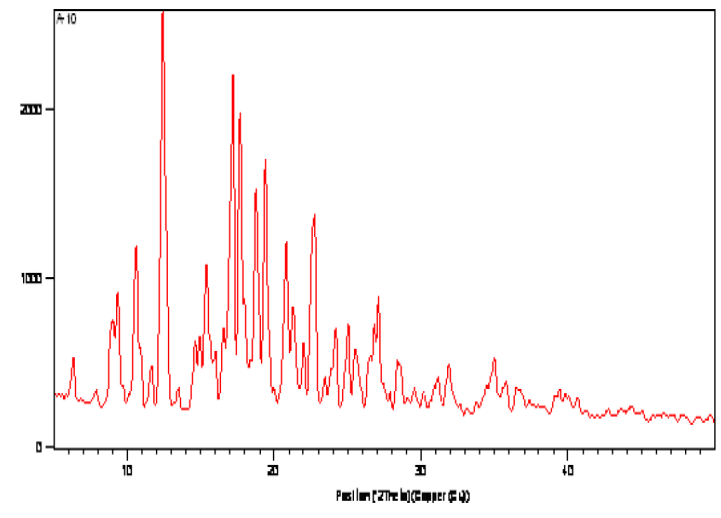

Figure 8: X-ray Diffraction pattern of Simvastatin.

\begin{tabular}{|c|c|}
\hline BOND & FREQUENCY(in $\left.\mathrm{cm}^{-1}\right)$ \\
\hline $\mathrm{OH}$ stretching & 3549 \\
\hline Aromatic $\mathrm{CH}_{3}$ group & 2968 \\
\hline Aromatic $\mathrm{C}=\mathrm{O}$ stretching & 1724 \\
\hline
\end{tabular}

Powder X-ray diffractograms of pure simvastatin and its inclusion complex with HP $\beta$-cyclodextrin (HP $\beta$ - CD) were shown in the Figure 8 and Figure 9 respectively.

The presence of numerous distinct peaks in the X-ray diffraction spectrum of the drug indicated that simvastatin was present as a crystalline material but the spectrum of simvastatin $+\mathrm{HP} \beta$-cyclodextrin $(\mathrm{HP} \beta$-CD) was characterized by the less intense diffraction peaks as compared to that of the pure drug thus it can be concluded that the drug was converted into amorphous state. $^{13}$

\section{CONCLUSION}

In the current generation of formulation development, poor bioavailability associated with poor solubility of drug is a major challenge. It is also a cause of higher therapeutic dose. Solid dispersion is very attractive approach for confronting this challenge which can be proved from the above study. It can be concluded from the above study that the solid dispersion of simvastatin can be prepared by various methods, of which the kneading method was best with HP $\beta$-CD in 1:1 (drug: polymer) ratio, in comparison with melting and physical mixture method. FTIR study showed that there is no interaction between the drug and polymer. Amorphization of drug was confirmed by PXRD study. The results revealed that there was an enormous enhancement of drugs solubility by solid dispersion. The highest solubility results were obtained with HP $\beta$-CD in comparison with PEG 6000 and $\beta$-CD. The results of solubility stud-

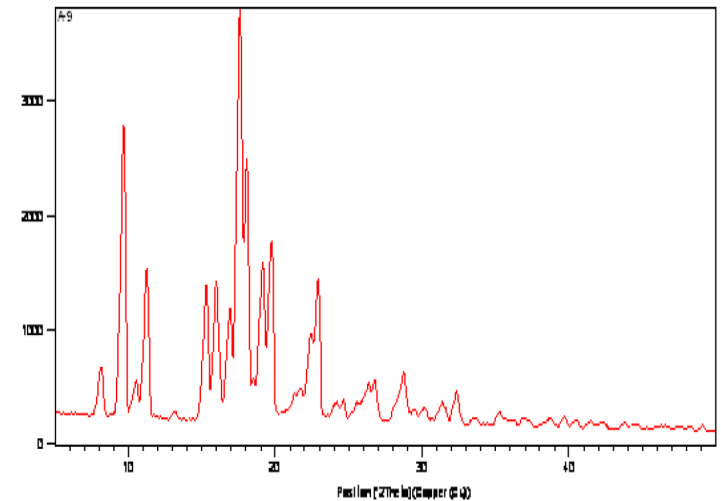

Figure 9: X-ray Diffraction pattern of inclusion complex of Simvastatin + HP $\beta-C D$.

ies were corroborated by the negative values of Gibbs free energy of transfer $\left(\Delta G \operatorname{tr}_{0}\right)$ in phase solubility study.

\section{ACKNOWLEDGEMENT}

The authors would like to thank Dr. Reddys' Pharmaceuticals' Ltd,. Hyderabad, India for supplying the pure drug simvastatin. The authors are thankful to Dr. Amit Roy for his technical support.

\section{CONFLICT OF INTEREST}

The authors declare none.

\section{ABBREVIATIONS}

SIM: Simvastatin; PEG: Polyethylene glycol; SD: Solid dispersion; FTIR: Fourier transfer infrared; PXRD: Powder X-ray diffraction; HP $\beta$-CD: (2-Hydroxypropyl)- $\beta$-cyclodextrin; HMG Co A: $\beta$ Hydroxy $\beta$-methylglutaryl-CoA; BCS: Biopharmaceutics Classification System; HPMC: Hydroxy propyl methyl cellulose; MC: Methyl cellulose; ANOVA: Analysis of varience; $\beta$-CD: $\beta$-cyclodextrin; UV: Ultraviolet.

\section{REFERENCES}

1. Allawadi D, Singh N, Singh S, Arora S. Solid dispersions: a review on drug delivery system and solubility enhancement. International Journal of Pharmaceutical Sciences and Research. 2013;4(6):2094.

2. Komal K, Kaur T, Singh AP, Singh AP, Sharma P. Enhancement of solubility and dissolution rate of simvastatin by using solid dispersion technique along with different combination of polymers. Journal of Drug Delivery and Therapeutics. 2018;8(2):32-40.

3. Shamsuddin MF, Ansari SH, Ali J. Atorvastatin solid dispersion for bioavailability enhancement. Journal of Advanced Pharmaceutical Technology and Research. 2016;7(1):22.

4. Sultana S, Saifuddin AH. Review article: Solid dispersion currently practiced in pharmaceutical field. International Journal of Advancements in Research and Technology. 2016;5(3):170-5.

5. Wairkar SM, Gaud RS. Solid dispersions: Solubility enhancement technique for poorly soluble drugs. International Journal of Research in Pharmaceutical and Biomedical Sciences. 2013;4(3):847. 
Affandi MM, Tripathy M, Shah SA, Majeed AB. Solubility enhancement of simvastatin by arginine: Thermodynamics, solute-solvent interactions and spectral analysis. Drug Design, Development and Therapy. 2016;10:959.

7. Rao M, Mandage $\mathrm{Y}$, Thanki $\mathrm{K}$, Bhise $\mathrm{S}$. Dissolution improvement of simvastatin by surface solid dispersion technology. Dissolution Technologies. 2010;61:27-34.

8. www.thinkSRS.com/products/MPA.htm

9. Meka L, Kesavan B, Kalamata VN, Eaga CM, Bandari S, Vobalaboina V, Yamsani MR. Design and evaluation of polymeric coated minitablets as multiple unit gastroretentive floating drug delivery systems for furosemide. Journal of Pharmaceutical Sciences. 2009;98(6):2122-32.

10. Chavhan V, Reddy K, Ahhirao K. Development of UV spectrophotometric methods and validation for estimation of simvastatin in bulk and tablet dosage form by absorbance maxima and area under the curve method. J Appl Pharm. 2014;6(1):55-64.

11. Veiga F, Teixeira-Dias JJ, Kedzierewicz F, Sousa A, Maincent P. Inclusion complexation of tolbutamide with $\beta$-cyclodextrin and hydroxypropyl- $\beta$ cyclodextrin. International Journal of Pharmaceutics. 1996;129(1-2):63-71.
12. Mandal D, Ojha PK, Nandy BC, Ghosh LK. Effect of carriers on solid dispersions of simvastatin (Sim): physico-chemical characterizations and dissolution studies. Der Pharm Lett. 2010;2(4):47-56.

13. Jun SW, Kim MS, Kim JS, Park HJ, Lee S, Woo JS, et al. Preparation and characterization of simvastatin/hydroxypropyl- $\beta$-cyclodextrin inclusion complex using supercritical antisolvent (SAS) process. European Journal of Pharmaceutics and Biopharmaceutics. 2007;66(3):413-21.

14. Higuchi TK. A phase solubility technique. Adv Anal Chem Instrum. 1965;4:117211.

15. Yadav VB, Nighute AB, Yadav AV, Bhise SB. Aceclofenac size enlargement by non aqueous granulation with improved solubility and dissolution. Arch Pharm Sci Res. 2009;1:115-22.

16. Wolozin B, Wang SW, Li NC, Lee A, Lee TA, Kazis LE. Simvastatin is associated with a reduced incidence of dementia and Parkinson's disease. BMC Medicine. 2007;5(1):20.

17. Loftsson T, Brewster ME. Pharmaceutical applications of cyclodextrins. 1 Drug solubilization and stabilization. Journal of Pharmaceutical Sciences. 1996;85(10):1017-25.

18. Rajewski RA, Stella VJ. Pharmaceutical applications of cyclodextrins. 2. In vivo drug delivery. Journal of Pharmaceutical Sciences. 1996;85(11):1142-69.

\section{PICTORIAL ABSTRACT}

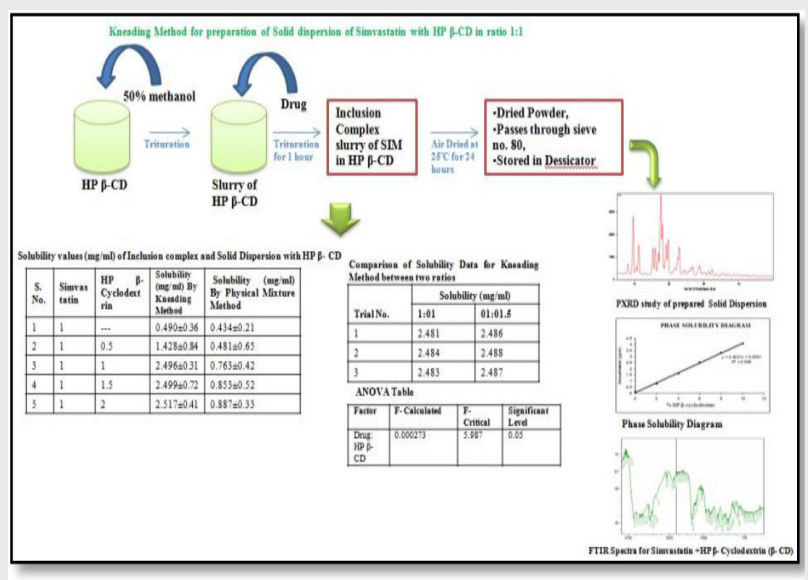

\section{SUMMARY}

- Solid dispersion of simvastatin was successfully prepared with HP $\beta$-CD in ratio $1: 1$, by using kneading method.

- From the FTIR study it was concluded that no interaction occurred between the ingredients of the formulations i.e. the drug was compatible with other ingredients used.

- The PXRD studies revealed that the crystalinity of the drug with HP $\beta$-CD has decreased as the PXRD spectrum of inclusion complex of simvastatin with HP $\beta$-CD showed less intense peaks as compared to that of the simvastatin.

- From the solubility and phase solubility's data, it can be concluded that there is a 6 fold increase in solubility of the drug at 1:1 ratio. With further increase in the amount of the HP $\beta$-CD (1:1.5) there was no significant increase in solubility. Only slight increase was found in the solubility with 1:2 ratio. The there was no significant difference between the inclusion complexes with molar ratio 1:1 and 1:1.5 which was also proved statistically. So the molar ratio 1:1 was selected.

Cite this article: Kesharwani D, Mishra S, Paul SD, Paliwal R, Satapathy T. Solubility Augmentation of Simvastatin by using the Marvelous Carrier Hydroxy Propyl $\beta$-cyclodextrin: Compatibility Study, Statistical and Spectral Analysis. Indian J of Pharmaceutical Education and Research. 2019;53(3 Supp 2):s231-s238. 